\title{
LA REFUNDICIÓN DEL REGLAMENTO BRUSELAS II BIS: DE NUEVO SOBRE LA FUNCIÓN DEL DERECHO INTERNACIONAL PRIVADO EUROPEO*
}

\author{
Elena RodRíguez PinEaU
}

SUMARIO: 1. INTRODUCCIÓN.-2. SEIS INTERVENCIONES FUNDAMENTALES.-2.1. La sustracción internacional de menores.-2.1.1. Mejoras en el proceso de restitución de menores.-2.1.2. Refuerzo del sistema de retorno (mecanismo de última palabra).-2.1.3. Valoración. 2.2. Medidas para la eliminación del exequatur.-2.2.1. Reconocimiento y ejecución automáticos (salvaguardando los derechos procesales).-2.2.2. Valoración.-2.3. Medidas para la mejora de la ejecución.-2.3.1. Desarrollo del proceso de ejecución.-2.3.2. Motivos de oposición a la ejecución.-2.3.3. Valoración.-2.4. Acogimiento transfronterizo.-2.5. Derecho de audiencia del menor.-2.6. Medidas de cooperación adicionales.-3. OTRAS MODIFICACIONES.-3.1. Reglas de CJI revisadas.-3.1.1. Competencia general.-3.1.2. Prórroga de la competencia.-3.1.3. Competencia residual y cuestiones accesorias.-3.2. En materia de medidas provisionales y cautelares. 3.3. Relaciones con otros actos.-4. CONCLUSIÓN.

\section{INTRODUCCIÓN}

Después de meses de trabajos preparatorios en junio de 2016 se publicó la propuesta de refundición del Reglamento Bruselas II bis $^{1}$. Como indica la propuesta, este texto resulta de un proceso de consulta pública y de un informe sobre la aplicación del Reglamento realizado por la Comisión en 2014. De igual modo, en la doctrina se habían apuntado ya sugerencias de reforma que señalaban algunos de los elementos más problemáticos de la aplicación del Reglamento (CE) núm. 2201/2003 del Consejo, de 27 de noviembre, relativo

* Este trabajo se enmarca en el proyecto de investigación La evolución de las instituciones jurídicas de protección de menores, DER2015-69261 (MINECO-FEDER). Elena Rodríguez Pineau es Profesora Titular de Derecho internacional privado en la Universidad Autónoma de Madrid. Correo electrónico: elena.rodriguez@uam.es.

1 Propuesta de Reglamento del Consejo relativo a la competencia matrimonial y a la responsabilidad parental, y sobre la sustracción internacional de menores (refundición), $\operatorname{COM(2016)~} 411$ final, disponible en http://eur-lex.europa.eu/legal-content/ES/TXT/PDF/?uri=CELEX:52016PC0411\&rid=1 (consultado el 21 de octubre de 2016). Los artículos de la propuesta se citan solo con su número para distinguirlos de los del Reglamento Bruselas II bis, que se acompañan de la abreviatura RBII bis: así, art. 1 (de la propuesta), art. 1 RBII bis (del Reglamento en vigor). 
a la competencia, el reconocimiento y la ejecución de resoluciones judiciales en materia matrimonial y de responsabilidad parental, por el que se deroga el Reglamento (CE) núm. 1347/2000², en adelante, RBII bis ${ }^{3}$. En este sentido, el texto presentado no trae grandes sorpresas puesto que recoge buena parte de los puntos débiles o de más difícil aplicación del Reglamento, incorporando igualmente algunos desarrollos resultantes de la jurisprudencia del Tribunal de Justicia de la Unión Europea (TJUE) ${ }^{4}$. Con todo, puede cuestionarse que se haya limitado su revisión a la parte relativa a la responsabilidad parental (y sustracción internacional de menores) y se haya mantenido intacta toda la sección relativa a los litigios matrimoniales ${ }^{5}$.

Como explica el propio documento, esta propuesta pretende mejorar la protección de los menores, en particular en aquellos supuestos en los que se han verificado fallos de funcionamiento del sistema tal y como han sido puestos de manifiesto por estudios académicos ${ }^{6}$ o realizados a instancia de las propias instituciones europeas ${ }^{7}$. El resultado de estos trabajos previos permi-

2 DO L núm. 338, de 23 de diciembre de 2003.

3 En España, Orejudo Prieto de los Mozos, P., «Diez años de aplicación e interpretación del Reglamento Bruselas II bis sobre crisis matrimoniales y responsabilidad parental (Análisis de los aspectos de competencia judicial internacional)», La Ley-Unión Europea, 2014, pp. 5-22; allende nuestras fronteras, KRUGER, Th. y SAMYN, L., «Brussels II bis : successes and suggested improvements», JPIL, vol. 12, 2016, núm. 1, pp. 132-168; CARPANETO, L., «On the Recast of Brussels II-bis Regulation's Regime on Parental Responsibility: few Proposals de iure condendo», en HeIDERHoff, B. y QueIRolo, I. (eds.), Party Autonomy in European Private (and) International Law, t. I, Aracne, 2015, pp. 247-288; DE BoER, Th. M., "What we should not expect from a recast of the Brussels II bis Regulation», NiPR, 2015, núm. 1, pp. 10-19; VAN LoON, H., «The Brussels IIa Regulation: towards a review?», en Cross-border activities in the EU-Making life easier for citizens, Workshop for the JURI Commitee, 2015, pp. 178-207 (http://www.europarl.europa.eu/RegData/etudes/STUD/2015/510003/IPOL_STU(2015)510003_EN.pdf, consultado el 21 de octubre de 2016).

4 El TJUE ha tenido ocasión de pronunciarse en veintiséis decisiones sobre el Reglamento Bruselas II bis, y solo en cuatro de ellas se trataba de cuestiones relativas a los procedimientos matrimoniales, lo que refuerza la idea de que la parte más problemática (y necesitada en su caso de revisión) es la relativa a la responsabilidad parental. A lo largo del trabajo se hará referencia a algunas de las decisiones más relevantes que están en la base de algunos de los cambios que se proponen en la refundición del texto. Para una visión de conjunto (hasta 2013) sobre la jurisprudencia del TJUE en interpretación de las reglas de responsabilidad parental del Reglamento nos remitimos a DuTTA, A. y ScHulz, A., «First Cornerstones of the Rules on Cross-Border Child Cases: the Jurisprudence of the Court of Justice of the European Union on the Brussels IIA Regulation from $C$ to Health Service Executive», JPIL, vol. 10, 2014, núm. 1, pp. 1-40.

5 Así, Kruger, Th. y Samyn, L., op. cit., nota 3, pp. 134 y ss.; Sánchez Jiménez, M. A., El divorcio internacional en la UE (Jurisdicción y ley aplicable), Cizur Menor, Aranzadi, 2013; OREJUdo PRIETO DE Los Mozos, P., op. cit., nota 3.

6 En el ámbito anglosajón y en materia de sustracción internacional de menores son varios los trabajos que han precedido a esta revisión, notablemente la monografía de Trimmings, K., Child Abduction within the European Union, Hart, 2013; o el informe del profesor BEAUMONT, P., «Conflicts of EU Courts on Child Abduction" financiado por la Nuffield Foundation (http://www.abdn.ac.uk/law/documents/ CPIL_Working_Paper_No_2016_1.pdf, consultado el 21 de octubre de 2016) publicado recientemente en Beaumont, P., Walker, L. y Holiday, J., "Conflicts of EU courts on EU child abduction: the reality of Articles 11(6)-(8) Brussels IIa proceedings accross the EU», JPIL, vol. 12, 2016, núm. 2, pp. 211-260.

7 Así, desde el Parlamento Europeo se han comisionado varios informes sobre cuestiones propias del Reglamento 2201/2003 como la sustracción internacional de menores dentro de la Unión Europea ( CCross-border Parental Child Abduction in the EU», Study for the LIBE Committee, disponible en http:// www.europarl.europa.eu/RegData/etudes/STUD/2015/510012/IPOL_STU\%282015\%29510012_EN.pdf, 
te a la Comisión identificar seis cuestiones principales que considera preciso abordar: la sustracción internacional de menores, la eliminación del exequatur, la ejecución de las decisiones extranjeras, la cooperación de autoridades, el acogimiento transfronterizo y la intervención del menor. Como indica la propuesta, la finalidad de esta revisión en última instancia sería la de proteger el interés superior del menor ya que los retrasos en los procedimientos, la mala cooperación entre las autoridades involucradas o la existencia de procedimientos intermedios, dificultan atender debidamente a esta consideración.

Prima facie pues la intención del legislador está clara. Ahora bien, cabe preguntarse si esta revisión no esconde otros fines menos centrados en el menor y que responden a intereses de naturaleza más política o relacionada con la integración europea. La propia propuesta, cuando presenta con detalle las seis áreas de intervención, las reformula de la siguiente manera ${ }^{8}$ :

1. Sustracción internacional de menores: introducción de medidas para aumentar la eficacia y mejorar el funcionamiento del mecanismo de prevalencia.

2. Eliminación del exequatur: con las salvaguardias adecuadas, que deberán invocarse en la fase de ejecución, es decir, para impugnar el reconocimiento o la ejecución de la resolución dictada en el Estado de origen o impugnar las medidas de ejecución concretas dictadas por el Estado en el que se solicita la ejecución, en el mismo y único procedimiento en el Estado en que se solicita la ejecución.

3. Ejecución efectiva de las resoluciones: introducción de medidas específicas destinadas a mejorar la eficacia de la ejecución propiamente dicha.

4. Acogimiento transfronterizo: creación de un procedimiento de aprobación autónomo que debe aplicarse a todos los acogimientos transfronterizos, acompañado de un plazo de ocho semanas para que el Estado miembro requerido dé curso a la petición.

5. Introducción de la obligación de que se dé al menor la oportunidad de expresar sus opiniones.

6. Cooperación de autoridades: clarificación [rectius, aclaración] de las tareas de las autoridades centrales y otras autoridades requeridas y adición de un artículo sobre los recursos adecuados.

La formulación de estas propuestas presenta un perfil bastante «armonizador» donde lo que se plantea de hecho es una homogeneización de los procedimientos para alcanzar una mayor eficacia en los procedimientos relativos a los menores. Y sin que esto sea necesariamente un punto de partida criticable, puesto que algunos de los elementos identificados son realmente un problema no solo desde el punto de vista de la integración europea sino

consultado el 21 de octubre de 2016, elaborado por el Institut Suisse de Droit Comparé, 2015) o el acogimiento transfronterizo ( Cross-border placement of children in the European Union», disponible en http://www.europarl.europa.eu/RegData/etudes/STUD/2016/556945/IPOL_STU(2016)556945_EN.pdf, dirigido por L. CARPANETO, 2016, consultado el 21 de octubre de 2016).

8 Propuesta, pp. 14-18. 
también desde la posición de los particulares, los menores y sus progenitores, que ven cómo se dilatan en el tiempo situaciones de crisis cuyo retraso siempre es perjudicial para el menor, lo cierto es que en muchas ocasiones la propuesta parece tener más en mente la construcción de un espacio judicial armonizado que la satisfacción de los derechos de las partes. En otros términos, es posible apreciar una tensión entre las dos finalidades del Derecho internacional privado europeo y puede cuestionarse si en determinados aspectos la propuesta no confiere una preeminencia a las políticas integradoras frente a la tutela de las situaciones jurídico-privadas que afectan al menor.

El trabajo analizará en primer lugar las seis áreas de intervención previstas por el legislador europeo, presentando sus elementos esenciales y los cambios que suponen frente a la normativa actual (infra 2). En segundo lugar, se contemplarán otros cambios que no responden a estas áreas de intervención pero que igualmente suponen cambios relevantes en el Reglamento Bruselas II (infra 3). Este análisis nos permitirá comprobar si realmente la refundición del RBII bis responde al interés superior del menor o, más bien, a una integración más armonizada que permita potenciar el principio del reconocimiento y la confianza mutuos (infra 4).

\section{SEIS INTERVENCIONES FUNDAMENTALES}

\subsection{La sustracción internacional de menores}

Resulta evidente que uno de los puntos más controvertidos de la reforma del RBII bis fue la introducción del ahora denominado mecanismo de «última palabra» del tribunal de la residencia habitual del menor inmediatamente anterior al traslado o retención. La práctica ha demostrado, además, que este mecanismo no ha encontrado una aplicación adecuada en la Unión Europea $^{9}$. De igual modo se constata que los procedimientos de restitución dentro de la UE no consiguen eliminar algunos de los problemas que se plantean en la aplicación del Convenio de La Haya de 1980 (CH1980). La propuesta pretende responder a estos dos grandes puntos así como a la mejora de la ejecución de las decisiones de retorno (infra 2.3). La propuesta reforma estructuralmente el Reglamento al introducir un capítulo III (nuevo) dedicado exclusivamente a la sustracción (mejor hubiera sido decir procedimientos de retorno) si bien las reglas de competencia judicial internacional, i. e. cómo la sustracción afecta a la competencia del tribunal de la residencia habitual del menor anterior al desplazamiento o retención, se siguen regulando en el capítulo II (en el art. 9, que apenas modifica el texto del art. $10 \mathrm{RBII}$ bis) ${ }^{10}$.

\footnotetext{
9 En este sentido, Beaumont, P., Walker, L. y Holiday, J., op. cit., nota 6, pp. 224 y ss.; TrimMINGS, K., op. cit., nota 6. Más positiva en la valoración de estas normas, CARPANETO, L., op. cit., nota 3, pp. 279 y ss.

10 El nuevo apartado (b) (iii) introduce una condición alternativa a las ya existentes para considerar que el menor ha adquirido nueva residencia habitual: por el transcurso de un año desde la localiza-
} 


\subsubsection{Mejoras en el proceso de restitución de menores}

Los arts. 26 y ss. constituyen una nueva sección que incorpora varias novedades: i) la concentración de la competencia para conocer de las acciones de restitución; ii) la imposición de un plazo uniforme para la resolución de la solicitud de restitución; iii) la posibilidad de adoptar medidas provisionales y cautelares y iv) la introducción de la mediación en el marco de los procesos de retorno. A ello se añade el refuerzo de disposiciones ya existentes anteriormente como la colaboración entre las autoridades involucradas en estos procesos v).

i) La propuesta de la concentración de la competencia, acompañada en muchos casos de la de la especialización, ha sido sostenida como un medio para mejorar los procedimientos de retorno ${ }^{11}$. El art. 22 de la propuesta introduce la concentración territorial, sin referencia a la especialización: «los Estados miembros garantizarán que su competencia [...] se concentre en un número limitado de órganos jurisdiccionales». Serán los Estados miembros los que comuniquen qué autoridades son las competentes en cada Estado ${ }^{12}$. De este modo, el legislador europeo introduce una armonización relativa, al imponer una obligación a los Estados miembros pero que, como indica el cdo. 26, se realizará «teniendo en cuenta en su caso, las estructuras internas de las correspondientes administraciones de justicia».

ii) Constatado que en el plazo de seis semanas previsto por el $\mathrm{CH} 1980 \mathrm{y}$ asumido por el RBII bis no es posible concentrar las fases de un procedimiento de restitución, $v$. gr. el proceso judicial de retorno, un eventual (y ahora único, art. 25.4) recurso y la ejecución de la decisión en su caso, la propuesta opta por una revisión pragmática, extendiendo los plazos hasta doce semanas (art. 23.1, seis semanas para cada instancia judicial desde la interposición de la demanda o recurso $)^{13}$ a las que sumar unas potenciales seis adicionales para la ejecución (art. 32.4).

iii) A la luz de los problemas observados en algunos de los casos que llegaron al TJUE, así como de las sugerencias realizadas para mejorar la tutela cautelar y provisional en estos supuestos, el art. 25.1 introduce una disposición relativa a las medidas provisionales y cautelares que pueden adoptarse durante este procedimiento. La práctica judicial ha demostrado en estos años la necesidad de aclarar qué medidas puede adoptar el juez del Estado

ción del menor, integración en el nuevo entorno y denegación de una demanda de restitución presentada por el titular del derecho de custodia por motivos distintos de los contemplados en el art. 13 del Convenio de La Haya de 1980.

11 VAn Loon, H., op. cit., nota 3, p. 204. Esta tendencia viene impulsada también desde la Conferencia de La Haya (véase el punto 5 de la Guía de buenas prácticas en virtud del Convenio de La Haya de 1980 sobre aspectos civiles de la sustracción de menores. Parte II: Medidas de aplicación, 2003) y en esta línea se enmarca la reciente reforma de la legislación española [art. 778 quater (2) LEC].

12 En España podría serlo el juzgado de primera instancia con competencia familiar en la capital de provincia donde esté el menor, en línea con la modificación de la LEC.

13 Cdos. 26 y 27. Esta posibilidad se había sugerido en la doctrina por van LoON, H., op. cit., nota 3, p. 205, y CARPANETO, L., op. cit., nota 3, p. 282. 
donde ha sido trasladado el menor. Pero también se había observado la necesidad de reforzar la posición de este juez para potenciar la restitución del menor en los supuestos en que se invocara el art. 13 (b) CH1980 y hubiera que adoptar medidas que garanticen la protección del menor tras su restitución. Que el juez del Estado donde se halla el menor pueda adoptar estas medidas, ejecutables en el Estado de origen del menor, permite favorecer el retorno del menor ${ }^{14}$.

iv) La introducción explícita de la mediación en el nuevo art. 23.2 como sistema que puede ayudar a resolver las sustracciones debe ser bienvenida ${ }^{15}$. Sin embargo, esta novedad resulta algo escasa en su formulación ya que no se aportan muchos elementos que permitan pergeñar el perfil de esta mediación: el órgano jurisdiccional examinará tan pronto como sea posible en el procedimiento ${ }^{16}$ si las partes, en interés superior del menor, están dispuestas a acudir a la mediación siempre que ello no retrase indebidamente el procedimiento. A estas consideraciones añade el cdo. 28 que será conveniente apoyarse en estructuras especializadas en mediación internacional. De este modo la disposición, que tampoco remite a la normativa de los Estados miembros, no permite concretar de manera clara quién y cómo debería procederse con esta mediación. Tal vez las diferencias existentes entre los Estados miembros impiden llegar más lejos, pero precisamente para potenciar este mecanismo sería conveniente que el legislador europeo fuera más concreto $^{17}$.

v) La propuesta incluye como uno de sus puntos fuertes la cooperación entre autoridades centrales o incluso la comunicación directa entre las autoridades judiciales (infra 2.6). En el marco de los procedimientos de retorno de menores esta colaboración se plasma en el art. 25.1 que debe leerse en conjunción con lo previsto en los arts. 63 y 64: facilitando la localización del menor, informando y ayudando a los progenitores que quieren ejecutar resoluciones relativas al retorno, facilitando las comunicaciones entre autoridades involucradas en el procedimiento de retorno, informando sobre el menor, etcétera.

14 Sobre la necesidad de introducir reglas específicas en tutela cautelar/provisional en el marco de los procedimientos de sustracción internacional, vAN LoON, H., op. cit., nota 3, pp. 193-194.

15 La importancia de la mediación en los litigios de familia también se ha señalado en la Conferencia de La Haya (Guía de buenas prácticas en virtud del Convenio de La Haya de 1980 sobre aspectos civiles de la sustracción de menores: Mediación, 2012). El reciente informe de la Comisión sobre la aplicación de la Directiva 2008/52/CE sobre ciertos aspectos de la mediación en asuntos civiles y mercantiles [COM (2016) 542 final] ha puesto de manifiesto que el ámbito primordial donde ha tenido impacto la Directiva ha sido, precisamente, en el de las disputas familiares (p. 5).

16 Sin embargo, en la explicación detallada de la propuesta se establece que es en las semanas en las que la autoridad central tiene que recibir y tramitar la solicitud, donde se debería proponer la mediación, velando por que esto no retrase el proceso (p. 14).

17 Algunos ordenamientos han desarrollado sistemas exitosos de mediación, como el holandés (véase el Centrum Internationale Kinderontvoering, http://www.kinderontvoering.org/, consultado el 21 de octubre de 2016), que podrían servir de pauta para una mínima armonización europea que terminara de asentar los esfuerzos que se están haciendo en algunos Estados miembros, v. gr. España [véase art. 778 quinquies (12) LEC]. 


\subsubsection{Refuerzo del sistema de retorno (mecanismo de última palabra)}

El sistema diseñado en los arts. 11(6) a 11(8) RBII bis ha sido criticado tanto en lo teórico como en su funcionamiento práctico, siendo uno de los puntos que más peticiones de reforma ha suscitado. El legislador europeo parece haber escuchado las objeciones concretas, pero no atiende a la de fondo, que cuestiona la necesidad y utilidad de un sistema que, hasta la fecha, no se ha revelado particularmente efectivo en los fines que perseguía ${ }^{18}$. Algunas de las críticas más estructuradas exigen restringir el procedimiento a los supuestos en que se invoque el art. 13(b) CH1980 y que se revise el art. 42 RBII bis para que el tribunal de origen haga constar en qué circunstancias se dio audiencia a las partes, por qué no se escuchó al menor y en qué sentido se valoraron las pruebas sobre las que se fundamenta el no retorno del menor. Adicionalmente se sugiere que esta decisión pudiera ser revisable en el Estado requerido por contrariedad con los derechos fundamentales ${ }^{19}$.

El nuevo art. 26 retoma en sus apartados 2 y 3 en términos casi idénticos los arts. 11.6 y 11.7 RBII bis, añadiendo la posibilidad de que las autoridades judiciales se comuniquen a través de la Red judicial europea, y la obligación de traducir la resolución a una lengua que acepte el Estado requerido. Las novedades más notables se incorporan en los apartados 1 y 4 . En el primero se introduce la obligación de especificar el artículo del CH1980 en el que se fundamenta la denegación de retorno. Por su parte, el apartado 4 revisa el art. 11.8 RBII bis para exigir que el Estado de la residencia habitual del menor analice la cuestión de la custodia teniendo en cuenta el interés superior del niño y las razones que se invocan en la resolución para denegar el retorno del menor. Al añadir la referencia al litigio sobre la custodia en el Estado de origen del menor, que deberá realizarse tras un cuidadoso examen del interés superior del niño ${ }^{20}$, la propuesta refuerza el correcto sentido del mecanismo europeo, evitando que cualquier resolución sirva para exigir el retorno del menor ${ }^{21}$. Pero la gran novedad se regula fuera del capítulo III, al incorporar el art. 40 la posible oposición a la ejecución de esta decisión (véase infra 2.3.2).

\subsubsection{Valoración}

Las objeciones de fondo al mecanismo introducido por el RBII bis para reforzar el CH1980 han encontrado escaso eco en el legislador europeo. La propuesta no solo no elimina los elementos más problemáticos del sistema

18 Beaumont, P., Walker, L. y Holiday, J., op. cit., nota 6, p. 258; van LoON, H., op. cit., nota 3, pp. 202-203.

19 Beaumont, P., Walker, L. y Holiday, J., op. cit., nota 6, p. 258.

20 Cdo. 30.

21 La formulación del art. 11.8 RBII bis podía hacer entender que el Estado de origen del menor ofrecía una «segunda instancia» para el progenitor left behind tras la denegación del retorno del menor secuestrado por el tribunal del Estado requerido. Esta percepción parecía haberse agudizado por el propio TJUE con su decisión en el asunto C-211/10 PPU, ECLI:EU:C:2010:400, paras. 51-67. Una reforma en este sentido había sido postulada por van LOON, H., op. cit., nota 3, p. 199. 
de retorno sino que lo refuerza, sin incorporar medidas que puedan matizar algunos excesos que una aplicación de estas normas puede producir, en particular teniendo en cuenta el profundo cambio social que se ha producido, siendo ahora en su gran mayoría el cuidador primario (la madre, generalmente) quien sustrae al menor. La reforma no introduce consideraciones de derechos fundamentales (en la línea del Tribunal Europeo de Derechos Humanos, TEDH) ni medidas de apoyo (como sugiere la Conferencia de La Haya $)^{22}$. Antes bien, refuerza un mecanismo que apuntala la preferencia por el tribunal de origen del menor desplazado (aunque se explicite que no tiene la última palabra sobre el retorno sino sobre la custodia) y que puede percibirse como poco compatible con el principio de confianza mutua, percepción que se agudiza cuando, en sede de ejecución, se abre una posible vía de oposición en el Estado requerido ${ }^{23}$. En otros términos, a pesar de que algunas de las medidas que se incorporan pueden servir para mejorar la situación actual (la concentración de la competencia o la tutela cautelar), la regulación sobre el proceso de restitución europeo parece seguir más orientada a resolver el equilibrio entre tribunales dentro de la UE que a asegurar que se persigue el interés superior del menor en estos supuestos.

\subsection{Medidas para la eliminación del exequatur}

\subsubsection{Reconocimiento y ejecución automáticos (salvaguardando los derechos procesales)}

Desde la UE se constata que el exequatur cuesta dinero y supone retrasos que no favorecen la situación del menor y su interés (a relacionarse con los progenitores, a estar en un entorno estable...) ${ }^{24}$. A pesar de las dudas que la desaparición del exequatur suscita ${ }^{25}$, el legislador europeo propone eliminarlo con carácter general aunque incorporando un sistema de oposición a la ejecución similar al establecido en otros textos europeos como el Reglamento Bruselas I bis ${ }^{26}$. La abolición del exequatur supone difuminar la especificidad que dentro del RBII bis presentan las resoluciones en materia de restitución de menores o ejecución del derecho de visita, que hasta ahora eran las únicas beneficiarias de una ejecución directa. Con todo, estas resoluciones siguen disfrutando de un régimen algo diferenciado en este nuevo esquema ${ }^{27}$.

El nuevo capítulo IV se divide en cuatro secciones que regulan el reconocimiento (arts. 27-29), la «ejecutoriedad» (arts. 30-36), la denegación del reco-

22 VAN LoON, H., op. cit., nota 3, p. 189.

23 Véase infra 2.3.2.

24 Propuesta, p. 8.

25 VAN LoON, H., op. cit., nota 3, p. 201.

26 Reglamento (UE) 1215/2012 del Parlamento Europeo y del Consejo, de 12 de diciembre, relativo a la competencia judicial, al reconocimiento y la ejecución de resoluciones judiciales en materia civil y mercantil (refundición), DO L núm. 351, de 20 diciembre de 2012.

27 Véanse los arts. 40 y 49 y las remisiones internas a otros artículos que estos realizan. 
nocimiento y la ejecución (arts. 37-47) y las disposiciones comunes (arts. 4854). La eliminación del exequatur tiene incidencia fundamentalmente en las últimas secciones.

Antes de abordar la eliminación del exequatur procede hacer referencia al sistema de reconocimiento. Una rápida revisión de la propuesta permite comprobar que se mantiene esencialmente el sistema de reconocimiento automático de resoluciones dictadas por tribunales de Estados miembros así como el reconocimiento incidental. Como novedad se refleja explícitamente la posibilidad de declarar la decisión no reconocible (art. 27) tal y como el TJUE había afirmado en el asunto $\operatorname{Rinau}^{28}$. En caso de oposición al reconocimiento se prevé la apertura de un procedimiento de oposición (i.e. el mismo que se tramita para oponerse a la ejecución, arts. 41 a 47) con unas causas tasadas de oposición (art. 28). La propuesta prevé igualmente la posibilidad de suspender este procedimiento en determinadas circunstancias (art. 29) incorporando a la impugnación de la decisión en el Estado miembro de origen otras dos situaciones: i) que se haya solicitado la tramitación del procedimiento de reconocimiento a título principal, o ii) que exista un proceso pendiente en otro Estado miembro para modificar la resolución o producir una nueva sobre la responsabilidad parental de un menor ante el tribunal competente sobre el fondo. Esta última incorporación puede resultar conveniente teniendo en cuenta que la resolución posterior sobre el menor recoge de manera más ajustada su situación actual.

La eliminación del exequatur conlleva un refuerzo del sistema de certificados, de modo que las decisiones que circulen lo hagan en condiciones de ser identificadas como ejecutivas de forma sencilla al tiempo que se garantiza que la persona frente a la que se solicita la ejecución pueda oponerse a esta para garantizar su derecho de defensa en el correspondiente procedimiento $^{29}$. La obtención del certificado para la ejecución retoma algunos de los elementos ya existentes en el RBII bis para las resoluciones en materia de sustracción de menores y derecho de visita, pero teniendo en cuenta que es aplicable a un número mayor de situaciones. El certificado para decisiones de responsabilidad parental se emitirá conforme al formulario del anexo II y el juez lo expedirá de oficio cuando la resolución adquiera fuerza ejecutiva si la situación tiene carácter transfronterizo; si la internacionalización del caso es sobrevenida a la resolución, la parte interesada deberá instar la solicitud del certificado (art. 53.2). Para poder expedir este certificado el juez deberá controlar que se han respetado los derechos de defensa. Esto presupone que verifique que se ha dado audiencia a las partes o, en caso de rebeldía, que se ha producido una notificación adecuada o, si no es el caso, que conste que el notificado ha aceptado de forma inequívoca la resolución (art. 53.4). Además, en los casos sobre responsabilidad parental el menor deberá haber tenido una auténtica y efectiva posibilidad de expresar sus opiniones (conforme al

\footnotetext{
28 Asunto C-195/08 PPU, ECLI:EU:C:2008:406.

29 Véase el cdo. 36.
} 
art. 20, véase infra 2.5). Y si la resolución es relativa al retorno del menor, habrá que comprobar además que el juez ha tenido en cuenta las razones y pruebas en que se fundamenta la resolución anterior dictada en otro Estado miembro en virtud del art. 13 CH1980 (art. 53.6). La expedición del certificado no es susceptible de recurso (art. 54.4) si bien, al igual que prevé actualmente el RBII bis, es posible su rectificación que, ahora se aclara, procede si existe un error material que suponga discrepancias entre la resolución y el certificado (art. 54.1). Novedosa, sin embargo, es la posibilidad de revocación del certificado cuando su emisión sea manifiestamente indebida conforme a los requisitos del Reglamento, lo que viene a introducir, de hecho, un posible recurso contra el certificado. El procedimiento de rectificación y de revocación están sujetos a la legislación del Estado miembro de origen del certificado (art. 54.3). Estos dos añadidos reproducen exactamente el tenor del art. 10 del Reglamento del título ejecutivo europeo ${ }^{30}$.

Una vez obtenido el certificado será posible su ejecución en los términos que prevé la sección III del capítulo (infra 2.3). Ahora bien, al igual que sucede con el reconocimiento, la parte frente a la que se solicite la ejecución podrá oponerse a esta en un procedimiento que la propuesta regula en términos similares a lo previsto en el actual RBII bis: se identifica un órgano competente (el art. 42 especifica que será el mismo ante el que se solicite la ejecución), se prevé la posibilidad de recurrir la decisión (arts. 44-45), así como la suspensión del procedimiento [art. 46, con un nuevo apdo. c) que refleja la causa de suspensión incluida en materia de reconocimiento, i. e. que esté pendiente un procedimiento ante el juez del fondo que pueda resultar en una decisión que modifique la pendiente de ejecución] y la ejecución parcial (art. 47) ${ }^{31}$. También se prevén motivos tasados de denegación de la ejecución (art. 40) ${ }^{32}$.

\subsubsection{Valoración}

Para la Comisión parece evidente que la eliminación del exequatur es un proceso inevitable, aunque sin argumentos contrastados con la realidad para fundamentar la adopción de esta medida, salvo tal vez los económicos del coste del procedimiento ${ }^{33}$. Lo cierto es que la renuncia al exequatur presupone un grado de integración más profundo entre los Estados miembros, que

\footnotetext{
30 Reglamento (CE) 805/2004, del Parlamento Europeo y del Consejo, de 21 de abril, por el que se establece un título ejecutivo europeo para créditos no impugnados, $D O$ L núm. 143, de 30 de abril de 2004. En este sentido tal vez pueda apuntarse, al igual que para este Reglamento, que la falta de respeto de las condiciones mínimas previstas por Bruselas II para otorgar el certificado sea motivo para solicitar la revocación.

31 Sobre esta modificación, véase CARPANETO, L., op. cit., nota 3, p. 277.

32 Infra 2.3 .2

33 Véanse pp. 14-15 de la propuesta, donde se alude a la madurez de la cooperación judicial y del nivel de confianza entre los Estados miembros, referencias que contrastan con las inquietudes reflejadas sobre el alcance del principio de confianza mutua tras casos como Aguirre Zarraga (asunto C-491/10 PPU, ECLI:EU:C:2010:828) o Purrucker II (asunto C-296/10, ECLI:EU:C:2010:665). Sobre esta tensión, CARO GÁNDARA, R., «De la desconfianza recíproca al reconocimiento mutuo: una laboriosa
} 
en materia de Derecho de familia puede no haberse alcanzado, y un nivel de confianza mutua que dista de estar presente como se verá de inmediato al analizar las salvaguardas a la ejecución. Más aún, la necesidad de incorporar medidas para la mejora de la ejecución pone de manifiesto que, probablemente, la parte más necesitada de mejora no fuera la del exequatur sino la de la ejecución en sentido estricto. En otros términos, cabe preguntarse si la eliminación del exequatur no es una medida que debe leerse en clave de integración más que de protección del interés superior del menor.

\subsection{Medidas para la mejora de la ejecución}

El legislador europeo es consciente de que la sola desaparición del exequatur no basta para resolver los problemas que actualmente encuentran los particulares: la tutela judicial no es efectiva porque existen problemas en la fase ejecutiva del proceso. Es por ello por lo que la propuesta introduce una serie de medidas en materia de ejecución, si bien el legislador europeo es consciente de las reticencias que los Estados miembros tienen a incorporar normas comunes en este punto ${ }^{34}$. Por ello, para abordar una mejora en esta fase del procedimiento, combina la remisión a la normativa nacional con reglas armonizadoras. Estas medidas son el objeto de la sección II del capítulo III de la propuesta, en lo que se denomina «ejecutoriedad» (arts. 30-36).

\subsubsection{Desarrollo del proceso de ejecución}

La ejecución de una decisión extranjera queda sujeta a la normativa del Estado miembro de ejecución, que determina el procedimiento en general, los medios de ejecución y sus modalidades en la medida en que no estén establecidas por el Reglamento (art. 31). Así, la competencia para la ejecución se determina por cada Estado miembro conforme a su normativa y se comunica a la Comisión (art. 32). Basta con la presentación del certificado (junto con una copia de la resolución que pretende ejecutarse en su caso) ante esta autoridad para que se pueda instar la ejecución en el Estado requerido; sin embargo, la autoridad solo podrá adoptar el primer acto de ejecución después de que se haya notificado a la parte requerida el certificado y la resolución (art. 35.1). Como el certificado se expide en la misma lengua que se redacta la resolución, la parte frente a la que se insta la ejecución puede solicitar su traducción y en tanto esta no llega, solo podrán adoptarse medidas cautelares (art. 35.2). También introduce una cierta armonización el art. 36 al regular la suspensión de la ejecución, que puede solicitar la parte frente a la que se pre-

\footnotetext{
transición (El Reglamento Bruselas II bis como banco de pruebas)», Diario La Ley, 31 de mayo de 2011, núm. 7641, Ref. D-226.

34 Véase Study on the assessment of Regulation (EC) No 2201/2003 and the policy options for its amendment, Final Report: Analytical annexes http://ec.europa.eu/justice/civil/files/bxl_iia_final_report_ analtical_annexes.pdf(consultado el 21 de octubre de 2016), p. 156.
} 
tende dicha ejecución si se verifica que: i) se ha suspendido la fuerza ejecutiva de la resolución en el Estado miembro de origen, o ii) existen circunstancias temporales que podrían poner en peligro el interés superior del menor ( $v . g r$. una enfermedad grave).

Esta incursión del legislador europeo es también evidente en lo relativo al límite temporal del procedimiento de ejecución, que se establece en seis semanas (art. 32.4). Es obvio que la demora en la efectiva ejecución puede resultar de las peculiaridades procesales de cada Estado, pero resulta evidente que aquí se procede a una armonización que obliga a los Estados miembros a asegurar que en ese plazo la parte podría oponerse, interponer posibles recursos - cuya viabilidad, al no estar expresamente limitados, dependería de la normativa de los Estados miembros- y proceder al cumplimiento voluntario. El plazo puede ser razonable en general pero puede suscitar más dudas la viabilidad del respeto a este plazo en los supuestos de sustracción internacional de menores, donde se verifica que esta es, sin duda, la parte más complicada del procedimiento.

Por último, estas reglas confieren al juez de la ejecución un poder adicional en la medida en que le permiten que adapte las medidas del juez de origen a su ordenamiento si es preciso (art. 33), precisión que solo se contempla en el RBII bis respecto de las decisiones relativas al derecho de visita ${ }^{35}$, para las que, de igual modo, se prevé la posibilidad de que sean declaradas provisionalmente ejecutivas aunque no lo sean conforme a la legislación del Estado miembro de origen (art. 30) ${ }^{36}$.

En esencia, aunque en lo fundamental se mantiene la aplicación del Derecho procesal de los Estados miembros, en estas primeras medidas se observa ya una incursión uniformadora del legislador europeo que se acentúa en lo relativo a la oposición a la ejecución.

\subsubsection{Motivos de oposición a la ejecución}

El procedimiento de ejecución no prevé un momento para oponerse a la ejecución sino que la parte frente a la que se solicita dicha ejecución deberá incoar el procedimiento de denegación de la ejecución en el que sí están previstos unos motivos de oposición (art. 32.3). A este procedimiento hemos hecho referencia supra 2.2.2, por lo que ahora centraremos el análisis en los citados motivos. Los motivos de oposición a la ejecución están tasados: los previstos en los arts. 38.1 (motivos de denegación de reconocimiento en materia de responsabilidad parental) y 40 (motivos de denegación de la ejecución). Los previstos en los apartados $a$ ), b) y c) del art. 38 ( $v$. gr. la contrariedad con el orden público, teniendo en cuenta el interés superior del menor, la indefensión producida por una incorrecta notificación y la falta de audiencia

\footnotetext{
35 Véanse el cdo. $35 \mathrm{y}$ el art. 33, que retoma el art. 48 RBII bis.

36 De hecho, esta disposición ya existe en el art. 41.1 RBII bis.
} 
de quien invoca su derecho de responsabilidad parental) no pueden invocarse frente a las resoluciones relativas a un derecho de visita o la restitución del menor (art. 40.1) que, en este sentido, siguen gozando de una especie de carácter preferente respecto del resto de decisiones en materia de responsabilidad parental. Paradójicamente, y al contrario de lo que ha sucedido hasta la fecha en los textos relativos a la ejecución de decisiones de otros Estados miembros, la propuesta no contempla la posibilidad de invocar motivos de oposición a la ejecución basados en la normativa estatal ${ }^{37}$, lo que pone de manifiesto la evidente voluntad del legislador europeo de evitar las tensiones entre Estados miembros derivadas de las diferentes percepciones en este sector del Derecho de familia.

En cuanto a los motivos del art. 38.1, además de los ya señalados, se mantiene la incompatibilidad de la resolución cuyo reconocimiento se solicita con la de otra posterior dictada en el foro o un tercer Estado, apartados d) y f). De este modo, el art 38.1 retoma esencialmente el art. 23 RBII bis, aunque de este desaparecen los apartados $b$ ), relativo a la audiencia del menor (ahora cubierta por la obligación de controlar por parte del juez que emite el certificado que dicha audiencia se ha producido en los términos del Reglamento, art. 53.5) y g) relativo al respeto del procedimiento previsto en el art. 56 (cuya desaparición se vincula a la profunda revisión que sufre este artículo en el nuevo art. 65, véase infra 2.4). Por su parte, el art. 40.2 incorpora una combinación de las cláusulas de orden público y del interés superior del menor. Conforme al art. 40.2 un cambio de circunstancias o la manifestación de la voluntad del menor pueden hacer manifiestamente incompatible la ejecución con el interés superior del menor, resultando manifiestamente contraria al orden público. Con esta disposición, el legislador europeo altera el juego habitual de las cláusulas generales del orden público y del interés superior del menor. Así, en el art. 38.1 este último es un elemento de ponderación del orden público, mientras que en el art. 40.2 el interés superior del menor se convierte en parte integrante de ese orden público. Esto no deja de ser llamativo cuando se trata de ejecutar resoluciones relativas al derecho de visita o al retorno de un menor secuestrado, para las que no puede invocarse el orden público (conforme al art. 38.2) pero sí un cambio de circunstancias tal que ponga en juego el interés superior del menor y haga la ejecución contraria al orden público.

De este modo el legislador europeo corrige el automatismo actual de la ejecución (a la que solo puede oponerse la existencia de una resolución posterior) con una valoración de carácter más sustantivo que considere el interés superior del menor. En este sentido, el artículo incorpora una petición reiterada, $v$. gr. la consideración de elementos posteriores a la obtención de la resolución, teniendo en cuenta la naturaleza esencialmente dinámica de la

37 Cdo. 37; véanse el art. 21.1 del Reglamento (CE) 4/2009 (relativo a la competencia, la ley aplicable, el reconocimiento y la ejecución de resoluciones y la cooperación en materia de alimentos, $D O$ L núm. 7, de 1 de 10 enero 2009), o el art. 41.2 del Reglamento Bruselas I bis, op. cit., supra nota 26. 
protección del menor ${ }^{38}$. Y de igual modo puede entenderse que el legislador europeo es sensible a las indicaciones del TEDH en cuanto a la necesidad de incorporar el interés superior del menor en la aplicación de las normas sobre restitución de menores. Pero estas nuevas disposiciones también pueden leerse como un mecanismo para reequilibrar la posición de los tribunales de los Estados miembros - en cierto modo sacrificada por la confianza mutua- en particular, suavizando los efectos del mecanismo de última palabra (supra 2.1.2).

\subsubsection{Valoración}

El análisis de las disposiciones refleja las contradicciones del legislador europeo: por una parte se puede constatar cómo la propuesta reconoce que el reconocimiento mutuo sin más no funciona ${ }^{39}$, lo que viene a confirmar que el proceso de ejecución directa del RBII bis no estaba lo suficientemente maduro (como ya se evidenció en el asunto Aguirre Zarraga) ${ }^{40}$ y que, probablemente aún ahora va a suscitar problemas. Así pues, el legislador europeo debe introducir un procedimiento uniforme de mínimos para la ejecución, procedimiento que necesita necesariamente del Derecho de los Estados miembros. Ahora bien, este margen de actuación que se deja a los ordenamientos nacionales, teniendo en cuenta las diferencias entre legislaciones, podría resultar peligroso si permite eludir la ejecución directa, por lo que el legislador europeo, al contrario de lo que ha hecho hasta la fecha, refuerza la armonización en materia de motivos de denegación de la ejecución, excluyendo toda remisión al Derecho nacional. Ciertamente, la modificación en lo relativo al interés superior del menor puede verse como una concesión al margen de valoración de los Estados miembros, pero esta percepción queda inmediatamente limitada cuando el legislador europeo exige que la valoración del interés superior del menor sea de entidad semejante a una vulneración del orden público. En esencia, a pesar de la referencia al interés superior del menor, estas modificaciones parecen reflejar más las tensiones entre integración y confianza mutua que una política de atender al citado interés del menor.

\subsection{Acogimiento transfronterizo}

Actualmente la regulación del acogimiento transfronterizo se limita al art. 56 RBII bis. Su remisión a la normativa nacional y las distintas formas

38 Con este posicionamiento la propuesta enmienda la jurisprudencia del TJUE, que había excluido toda posibilidad de considerar estas circunstancias sobrevenidas por el juez del Estado requerido, permitiendo tal posibilidad solo ante el tribunal del Estado de origen de la resolución. Véase el asunto C-211/10 PPU, ECLI:EU:C:2010:800, párrs. 80 a 83.

39 Como indica la propia introducción a la propuesta, «se requiere una armonización mínima para alcanzar el objetivo del reconocimiento mutuo de decisiones», p. 7.

40 Supra nota 32. 
de resolver su aplicación en los Estados miembros ha generado problemas concretos de aplicación ${ }^{41}$. Así se evidenció en el asunto HSE, que llegó al TJUE en $2012^{42}$. En particular, la principal dificultad se ha observado respecto de cómo debe producirse la aprobación por parte del Estado donde va a ser trasladado el menor para ser acogido procedente de otro Estado miembro donde se dicta la medida de protección. En la Sentencia HSE el TJUE introdujo una serie de aclaraciones relevantes: el Estado miembro requerido no puede oponerse a la petición del Estado de origen y debe asegurarse de que su normativa no impide el efecto útil del Reglamento (párrs. 82 y 79). El TJUE diferencia entre Estado miembro que exige intervención de autoridad pública, en cuyo caso esta deberá prestar su consentimiento, y el que no, bastando entonces con que sea informado. Estas actuaciones quedan sujetas a la ley del Estado miembro requerido, pero en todo caso deben realizarse por una autoridad pública y obtenerse con anterioridad al acogimiento. Cuando no se ha interpretado correctamente el alcance de la aprobación debería ser posible remediarla a posteriori, no así cuando dicha aprobación no se ha obtenido en absoluto, en cuyo caso habría que recomenzar el procedimiento.

El segundo elemento dudoso, una vez obtenida la aprobación del Estado requerido, se refería a la necesidad de obtener la homologación de la decisión del Estado de origen que ordena el acogimiento transfronterizo. El TJUE aclaró que el reconocimiento de esta medida es automático, a menos que se dicte una orden de no reconocimiento ${ }^{43}$. Sobre la necesidad de obtener el exequatur de la decisión del Estado miembro de origen, el TJUE impuso su obtención a la vista de que el acogimiento puede suponer el ejercicio de medidas coactivas sobre un menor por parte del Estado requerido y ello exigiría el exequatur, incluso cuando la situación fuera de gran urgencia. Para mejor proteger al menor en estas circunstancias, el TJUE estima que el recurso contra la declaración de ejecutoriedad no puede tener efecto suspensivo y que el Estado requerido puede adoptar medidas provisionales conforme al art. 20 RBII bis mientras dure el procedimiento ${ }^{44}$. En todo caso, es conveniente recordar las especiales circunstancias del caso HSE, que suponía ingresar a la menor en un centro de internamiento, lo que limitaba su libertad de movimientos, circunstancia que no se dará necesariamente en todos los supuestos de acogimiento transfronterizo.

Con estas premisas de partida, el legislador europeo aborda la reforma del art. 56 RBII bis en un nuevo art. 65 que introduce un proceso uniforme con una serie de elementos fundamentales ${ }^{45}$. En primer lugar se impone la

41 Véase el informe del Parlamento, op. cit., supra nota 7. En la doctrina, Herranz BaLlesTERos, M., "Cross-border Placement of Children: the Current Situation in Spain», YPIL, vol. 17, $2015-$ 2016, pp. 449-461; ForCada MiRANDA, J., «Revision with respect to the cross-border placement of children», NiPR, 2016, pp. 36-42.

42 Asunto C-92/12 PPU, ECLI:EU:C:2012:255.

43 DutTa, A. y Schulz, A., op. cit., nota 4, pp. 33-34.

44 Asunto C-92/12 PPU, HSE, cit., supra nota 42, párrs. 107-133.

45 Sobre la necesidad de armonizar el procedimiento a nivel europeo, ForCADA MiRANDA, J., op. cit., nota 41. El nuevo art. 65 alinea el Reglamento con el art. 33 del Convenio de La Haya relativo a la 
obtención de la aprobación de la autoridad competente del Estado miembro requerido mediante el conducto de las autoridades centrales de los dos Estados miembros (párr. 1). Este procedimiento queda sujeto al Derecho del Estado miembro requerido (párr. 5) y solo tras esta aprobación podrá el Estado miembro requirente dictar la correspondiente decisión sobre el acogimiento (párr. 3). La autoridad requirente tendrá que presentar los documentos y solicitud traducidos a una lengua que el Estado requerido haya declarado que acepta y la autoridad requerida dispondrá de plazo de ocho semanas para decidir sobre la aprobación, salvo que circunstancias excepcionales lo impidan (párrs. 2 y 4). De este modo el nuevo artículo recoge parte de la jurisprudencia del asunto HSE en lo relativo a la obtención de la aprobación de la autoridad competente del Estado requerido. La ubicación de este precepto, dentro de la cooperación de autoridades, explica que no se haga referencia alguna a la declaración de ejecutoriedad de la medida una vez adoptada. Pero a la luz de las consideraciones realizadas supra [en particular la eliminación del art. 23.1.g) RBII bis], resulta evidente que no será preciso el exequatur tampoco para estos supuestos, quedando así anulada la jurisprudencia del TJUE ${ }^{46}$.

Tampoco se alude en el cuerpo del Reglamento a cómo se va a garantizar el respeto de los derechos del menor a la luz de lo previsto en la Convención de Derechos del niño (arts. 8 y 9) y la Carta de derechos fundamentales de la Unión (art. 24.3) a los que sí se refiere el cdo. 51 y que suponen el derecho a mantener contacto con ambos progenitores así como la continuidad en la educación del menor, su contexto étnico, religioso, cultural y lingüístico. Esta garantía de los derechos del menor parece pasar a un segundo plano frente a una necesaria coordinación de las autoridades que mejore el sistema de acogimiento transfronterizo. Y de nuevo podemos preguntarnos si esta actuación, en un orden procesal o de cooperación de autoridades (pues esta disposición se inserta en el capítulo V), refleja o concreta el interés superior del menor ${ }^{47}$. Si en toda actuación relativa al menor la protección de sus derechos es fundamental, en este caso es especialmente relevante puesto que un acogimiento transfronterizo puede tener unas consecuencias radicales en lo que respecta al contacto con los progenitores, el desarrollo educativo del menor, etcétera.

competencia, la ley aplicable, el reconocimiento, la ejecución y la cooperación en materia de responsabilidad parental y de medidas de protección de los niños, de 19 de octubre de 1996, BOE núm. 291, de 2 diciembre de 2010, pp. 99837 y ss.

${ }_{46}$ Tal vez el alcance de esta solución sea excesivo, pues quienes habían postulado la eliminación del exequatur lo sugerían para aquellos supuestos en que se solicite el acogimiento sin privación de libertad del menor, véase DutTA, A. y Schulz, A., op. cit., nota 4, p. 37.

47 Insistiendo sobre la importancia de que el interés superior del menor y el ejercicio de sus derechos fundamentales sean consideración primaria en la regulación de esta materia, HeRRANZ BALLESTERos, M., op. cit., nota 41, pp. 460-461. 


\subsection{Derecho de audiencia del menor}

Desde el asunto Aguirre Zarraga ${ }^{48}$ es evidente que el tema del derecho de audiencia del menor es una cuestión muy sensible y para la que no existe un consenso sobre su alcance entre los Estados miembros. Recordando rápidamente el asunto Aguirre Zarraga, la menor de padre español y madre alemana, había sido llevada por su madre a Alemania. El padre solicitó su retorno y la madre se opuso, lo que dio lugar al inicio de un procedimiento en España para establecer la custodia (y retorno) de la menor a favor del padre. A este procedimiento se convocó a madre e hija, pero no comparecieron por el temor de la madre de que no pudiera salir posteriormente de España. Solicitada la ejecución de la decisión española en Alemania, el tribunal alemán consideró que, a pesar de la obligatoria ejecución de la medida conforme al Reglamento, podía oponerse a dicha ejecución por la vulneración del derecho de audiencia del menor, que es parte fundamental del orden público alemán. El TJUE rechazó esta interpretación estableciendo que lo importante no es la audiencia efectiva del menor (porque el art. 24 de la Carta europea no impone necesariamente esta audiencia) sino la posibilidad de que el menor pueda expresar su opinión de manera genuina y efectiva, atendiendo a su edad y madurez teniendo en cuenta su interés superior. Estas pautas dejan un margen de apreciación al tribunal que debe realizar la audiencia.

El nuevo art. 20 de la refundición del Reglamento se titula «Derecho del menor a expresar sus opiniones» pero en la explicación que precede a la propuesta resulta convenientemente reformulado como «obligación de que se dé al menor la oportunidad de expresar sus opiniones». Este punto de la reforma es muy sensible puesto que están en juego la protección de derechos fundamentales y el principio de confianza mutua. Conviene señalar que en el texto actual del RBII bis la obligación solo existe en los procedimientos de restitución del menor sustraído (tal y como se mantiene ahora en el art. 24), mientras que la propuesta incorpora con carácter general este derecho/obligación al final de la sección III del capítulo II (relativo a las disposiciones comunes en sede procesal).

La propuesta asegura que el Reglamento no tiene por objeto definir cómo debe oírse al menor (si por juez en persona o por un experto que informe al juez, si en audiencia o en otro lugar, etc. ${ }^{49}$ de manera que «no modifica en absoluto las normas y prácticas de los Estados miembros sobre la audiencia de los menores, pero exige el reconocimiento mutuo de los ordenamientos jurídicos». Esta nueva obligación, sugiere la propuesta, no lo es realmente puesto que los Estados miembros están vinculados por la Convención de Naciones Unidas de Derechos del Niño (CDN) y, por tanto, es ya una imposición

\footnotetext{
48 Asunto C-491/10 PPU Aguirre Zarraga, supra nota 33, párrs. 60-67.

49 Véase el cdo. 23, complementado por la referencia prevista en el cdo. 24 a los procedimientos establecidos en el Reglamento (CE) núm. 1206/2001 del Consejo, de 28 de mayo, relativo a la cooperación entre los órganos jurisdiccionales de los Estados miembros en el ámbito de la obtención de pruebas en materia civil o mercantil (DO L núm. 174, de 27 de junio de 2001), si procede.
} 
asumida por los Estados miembros. Adicionalmente la propuesta establece que esta obligación debe interpretarse a la luz de la Carta de derechos fundamentales de la UE, que distingue entre cuándo debe darse al menor la oportunidad de manifestar su opinión (i.e. si el menor tiene un juicio y edad suficientes) y cómo debe valorar el juez esta (dependiendo de la edad y madurez del menor). Estos extremos deben recogerse en la resolución, de manera que el juez que emite el certificado pueda constatar su cumplimiento.

En esencia, el derecho del menor a ser escuchado, que es un elemento fundamental para establecer cuál es su interés superior, se plantea como una obligación cuyo cumplimiento debe asegurar para toda la Unión Europea el juez del Estado que dicta la resolución, sin que ningún otro Estado pueda controlar la actuación del juez de origen de la sentencia (supra 2.3.2). Y precisamente este enfoque pone de manifiesto cómo el legislador europeo necesita forzar la confianza mutua con una medida armonizadora que evite las tensiones que existen entre los Estados miembros a la hora de valorar este derecho del menor.

\subsection{Medidas de cooperación adicionales}

La introducción explicativa de la propuesta pone de relieve que la actual norma sobre cooperación entre autoridades, art. 55 RBII bis, no resulta satisfactoria en distintos sentidos: no es suficientemente clara, no proporciona base jurídica en los Estados miembros para muchas actuaciones y ello ha provocado retrasos que van en perjuicio del interés superior del menor ${ }^{50}$. Es por ello que la propuesta introduce una serie de medidas relativas a la intervención de las autoridades centrales y otras autoridades, con la idea de que una efectiva tutela de los intereses del menor pasa por la colaboración entre autoridades ya que ello facilita la adopción de medidas, reduce los tiempos, etcétera ${ }^{51}$.

Estas modificaciones vienen además refrendadas por la intervención del TJUE, que ha sido particularmente activo en la promoción de esta colaboración entre autoridades. Ya en el asunto $A^{52}$ indicó la pertinencia de comunicar al tribunal competente sobre el fondo la adopción de una medida cautelar, bien de manera directa, bien indirecta a través de las autoridades centrales o la red judicial europea; también en Purrucker $I I^{53}$ se señala la conveniencia de comunicación para establecer quién es el primer tribunal y poder aplicar la regla de la litispendencia.

El resultado de esta intervención se plasma en el capítulo V (arts. 60-67) que pretende responder a cuatro preguntas fundamentales: quién puede soli-

\footnotetext{
50 Propuesta, p. 5.

51 Véanse los cdos. 41 y ss.

52 Asunto C-523/07, A, ECLI:EU:CL:2009:225, párrs. 54-56.

53 Asunto C-296/10, supra nota 33, párr. 81.
} 
citar ayuda, qué puede pedir, a quién y cómo hacerlo. Así, tras identificar a las autoridades centrales de cada Estado miembro (art. 60), se procede a delimitar cuáles son las tareas generales (art. 62) y las específicas de cooperación en casos de responsabilidad parental (arts. 64 y 65). Si las tareas generales estaban ya identificadas en el art. 54 RBII bis (nuevo art. 62), las actuaciones de cooperación específica resultan más precisadas, de manera que se incluyen algunas como facilitar la localización de un menor [apdo. a)] y garantizar que el expediente incoado por la Autoridad Central en materia de sustracción se complete en un plazo de seis semanas [apdo. g)]. La cooperación en la recogida e intercambio de información [art. 62.1.b)] se desarrolla ampliamente en el art. 63 para incluir la elaboración de informes sobre la situación del menor (por ejemplo, respecto de procedimientos pendientes o resoluciones adoptadas sobre este), informes recabados para proteger al menor (en relación con sus familiares, progenitores, hermanos...) o para garantizar el ejercicio del derecho de visita o la posibilidad de acceder a dicho derecho por parte de una persona que así lo desee ${ }^{54}$.

Junto a una mayor precisión de cuáles sean las posibles medidas y vías de colaboración, hay dos elementos esenciales para que se mejore dicha colaboración: el lingüístico y el temporal, que la propuesta recoge debidamente. Así, se prevé la traducción de los documentos pertinentes a un idioma del Estado requerido o que este acepte (art. 64.4) y un límite temporal de dos meses para que la autoridad preste la colaboración requerida desde otro Estado miembro salvo que existan circunstancias excepcionales. Por último, y de no menor entidad que los elementos anteriores, el art. 61 introduce una disposición muy relevante sobre la financiación de estas medidas, ya que se prevé que los Estados miembros dedicarán los medios (personales y patrimoniales) necesarios para llevar a cabo las disposiciones que les impone el Reglamento. Estas disposiciones ponen de manifiesto que hay una voluntad de mejora pero que, en última instancia, su efectividad depende de los Estados miembros, puesto que si no dotan de medios económicos y personales a las Autoridades Centrales, todas estas disposiciones carecerán de resultado práctico alguno.

\section{OTRAS MODIFICACIONES}

Sin ser parte del bloque de las seis medidas «estrella» de revisión del reglamento, la propuesta introduce una serie de modificaciones que en algunos casos responden a la incorporación de la jurisprudencia del TJUE en interpretación del RBII bis.

54 Estas disposiciones alinean claramente la propuesta de refundición del Reglamento con las disposiciones del Convenio de La Haya de 1996 en materia de cooperación de autoridades (véanse en particular los arts. 30-35). 


\subsection{Reglas de CJI revisadas}

\subsubsection{Competencia general}

La regla fundamental del sistema RBII bis en materia de responsabilidad parental permanece inalterada, puesto que la residencia habitual del menor es el elemento que determina la competencia judicial sobre dicho menor. Ahora bien, sí se modifica de manera relevante la interpretación de la actual regla sobre el alcance de la jurisdicción de este tribunal. En efecto, el legislador europeo introduce en la propuesta un cambio respecto de la perpetuatio iurisdictionis del tribunal de la residencia habitual. El art. 8 del RBII bis impone la competencia del tribunal de la residencia habitual del menor al tiempo de la presentación de la demanda, de manera que un cambio legal en dicha residencia no altera la jurisdicción de este tribunal. Esta regla de la perpetuatio iurisdictionis, muy asentada en los ordenamientos occidentaleseuropeos, no es la que recoge, por el contrario, el Convenio de La Haya de 1996 en su art. 5.2, donde un cambio legal de residencia del menor supone una modificación de la competencia judicial incluso si el procedimiento estuviera pendiente. Esta discrepancia había suscitado algunas voces críticas, en particular cuando el menor trasladara su residencia a un Estado contratante del citado convenio ${ }^{55}$. El nuevo art. 7 (art. 8 RBII bis) introduce esta nueva regla aunque con alguna matización que incorpora el cdo. 15: el cambio de competencia deberá producirse esté o no iniciado un procedimiento respecto del menor. Ahora bien, en aquellos casos en que la causa esté pendiente, puede resultar conveniente que el tribunal que está conociendo mantenga su competencia (en particular, si el procedimiento está cercano a la conclusión) si ello redunda en el interés superior del niño. Como indica el citado considerando, esta previsión puede ser de especial relevancia en los casos de reubicación transfronteriza. Esta solución merece una valoración positiva, teniendo en cuenta además que alinea las soluciones del Reglamento con las del Convenio de La Haya, evitando así posibles conflictos que ahora pueden producirse.

\subsubsection{Prórroga de la competencia}

A diferencia de la regla general, el actual art. 12 RBII bis en materia de prórroga de la competencia (presentada en la propuesta como «elección de órgano jurisdiccional para los procedimientos autónomos y accesorios») es objeto de una revisión más evidente en el nuevo art. 10, que incorpora parte de la jurisprudencia del $\mathrm{TJUE}^{56}$. A pesar de estos cambios la esencia del art. 12 RBII bis se mantiene en el art. 10.

55 De Boer, Th. M., op. cit., nota 3, pp. 15-18; van LoON, H., op. cit., nota 3, p. 192.

56 Así los asuntos C-436/13, ECLI:EU:C:2014:2246; C-656/13, ECLI:EU:C:2014:2364; C-215/15, ECLI:EU:C:2015:710. 
El art. 12 RBII bis contempla dos supuestos de sumisión: i) a los tribunales de la acción matrimonial para que conozcan conjuntamente de la acción matrimonial y de la relativa a la responsabilidad parental (apdo. 1), y ii) a los tribunales que elijan las partes, con determinadas limitaciones, para la acción de responsabilidad parental (apdo. 3). La propuesta no altera esta estructura, aunque sí incorpora algunos elementos novedosos. En cuanto a la sumisión (por conexidad) a los tribunales del Estado miembro que conocen de una acción matrimonial conforme al art. 3 RBII bis para los litigios relativos a la responsabilidad parental, el art. 10.1 solo matiza el actual texto (art. 12.1 RBII bis) con la introducción de una condición adicional para entender que existe la sumisión: "A más tardar, en el momento de someter el asunto ante el órgano jurisdiccional o, cuando la ley de dicho Estado lo establezca, durante el procedimiento». Idéntica matización se incorpora para el supuesto del art. 10.3 ${ }^{57}$. Este apartado también se modifica en su primer párrafo, simplificando su tenor (se elimina la referencia a «en procedimientos distintos de los contemplados en el apartado 1») de manera que no quepa duda de la posibilidad de recurrir a este foro aunque el tribunal elegido no esté conociendo de otra acción a la que acumular la relativa a la responsabilidad parental, tal y como había aclarado el TJUE en su jurisprudencia y se había pedido por la doctrina ${ }^{58}$.

El cdo. 16 insiste en el carácter excepcional de este foro, que supone una quiebra al principio de proximidad, lo que explica la necesidad de cesar la competencia en cuanto exista una resolución definitiva sobre el menor y poder retornar así a la exigencia de la proximidad. En este sentido deben entenderse los dos apartados que se incluyen en el nuevo art. 10, que incorporan i) una regla sobre la cesación de competencia en los supuestos del apartado 3 ( $v . g r$. cuando el procedimiento resulte en una decisión final $)^{59}$, del mismo modo que en el apdo. 2 se contemplan las causas que implican la cesación de la competencia en los supuestos en que conoce el tribunal de la acción matrimonial, y ii) una obligación de recoger por escrito ( «hará constar en acta») el acuerdo de sumisión de las partes de conformidad con la ley del Estado miembro del tribunal prorrogado. El TJUE había establecido la necesidad de interpretar de manera estricta el carácter inequívoco de la aceptación de la competencia, lo que supone, como mínimo, conocimiento de que se está desarrollando el proceso, sin que este conocimiento por sí mismo suponga una aceptación ${ }^{60}$. En este sentido, esta exigencia de un acuerdo recogido en acta permite salvaguardar todas las dificultades interpretativas de una «aceptación inequívoca» de la competencia del tribunal prorrogado.

57 Con esta formulación el legislador europeo establece en términos más flexibles para los Estados miembros la fijación temporal que había realizado el TJUE en el asunto C-656/13, cit., supra nota 56, párr. 56, al establecer que el límite se halla «en el momento en que se presente ante el tribunal elegido el escrito de demanda o un documento equivalente».

58 Asunto C-656/13, cit., supra nota 56, párrs. 40-52; CARPANETO, L., op. cit., nota 3, p. 266.

59 Tal como resulta de la jurisprudencia del asunto C-436/13, cit., supra nota 56.

60 Asunto C-215/15, cit., supra nota 56, párrs. 41 y 42. 
El art. 10 concluye con un sexto apartado, que corresponde al art. 12.4 RBII bis, que permite entender que la sumisión ante los tribunales de un Estado miembro (en las condiciones previstas en el artículo) es en interés superior del menor aun cuando el menor tenga su residencia habitual en un Estado no contratante del CH1996. Sobre esta extensión del alcance de la sumisión en el ámbito del RBII bis ya se hizo crítica en su momento ${ }^{61}$, y resulta revelador que se mantenga este foro en la propuesta de refundición. Por el contrario, la propuesta delimita mejor el juego de las reglas de sumisión del Reglamento y del CH1996 en el art. 75 (actual art. 61 RBII bis), introduciendo una regla que asegura la aplicación del Convenio en casos de sumisión regulados en dicho texto (infra 3.3).

\subsubsection{Competencia residual y cuestiones accesorias}

La propuesta mantiene en el art. 13 (art. 14 RBII bis) la regla sobre la posible asunción de competencia (residual) por los tribunales de los Estados miembros conforme a su normativa si ningún tribunal de la Unión pudiera declararse competente para conocer de la acción de responsabilidad parental conforme a las normas del RBII bis. Sí resulta novedosa, por el contrario, la aclaración que el legislador introduce en el cdo. 19: «Siempre que se haga referencia a la "competencia en virtud del presente Reglamento" en las cuestiones de responsabilidad parental, dicha referencia debe incluir los artículos 7 a 14, es decir, abarcar asimismo la competencia residual en virtud del Derecho nacional permitida por el artículo 13 del presente Reglamento y la competencia establecida en virtud de una transferencia de competencia». De este modo se refuerza la interpretación de que las normas estatales en cierto modo han dejado de serlo en la medida en que su aplicación depende de la autorización del propio Reglamento.

Para concluir apuntaremos cómo el legislador europeo introduce un nuevo art. 16 fuera de la sección relativa a la competencia judicial internacional en materia de responsabilidad parental, que permite atribuir competencia accesoria a un tribunal que esté conociendo de una causa no incluida en el ámbito de aplicación del RBII bis pero que deba resolver con carácter incidental/previo una cuestión que sí lo esté. El cdo. 22 aclara que la competencia así conferida (incluso si no tuviera competencia conforme al Reglamento) producirá una resolución con efectos solo para el procedimiento de que se trate, ejemplificando con un caso de litigio en materia de sucesiones que afecta al niño y para el que sea preciso designar a un tutor ad litem para que lo represente en el marco de dicho procedimiento ${ }^{62}$. Esta nueva regla, que se

61 Rodríguez Pineau, E., «El nuevo reglamento comunitario sobre litigios matrimoniales y responsabilidad parental», La Ley-actualidad, núm. 5944, 2004, pp. 1721-1731. Igualmente DE BoER, Th. M., op. cit., nota 3, pp. 13-14, critica el extenso ámbito de aplicación territorial del RBII bis, considerando que no favorece la tutela de las partes, al resultar más complicado que fuera de la UE se reconozca la sentencia dictada sobre este (y otros) foro(s) de competencia.

62 Esta explicación remite directamente al asunto C-404/14, ECLI:EU:C:2015:653, si bien en este asunto el TJUE parece apuntar que la competencia se asumiría por el juego del art. 12.3 RBII bis (párr. 37). 
acerca a una regla de conexidad procesal (pero sin conferir realmente una competencia a título principal, puesto que su alcance está limitado al proceso para el cual se abre la competencia), puede servir para evitar las dilaciones que supondría tener que suspender el procedimiento hasta que el tribunal competente para decidir sobre el menor (en otro Estado) adoptara la correspondiente medida. Así pues, el legislador introduce una regla que efectivamente favorece al menor en tanto permite la resolución del litigio que afecta al menor de manera más rápida ${ }^{63}$.

\subsection{En materia de medidas provisionales y cautelares}

La regulación de las medidas provisionales y cautelares es objeto de una importante revisión en la propuesta. No solo se añade el ya citado art. 25 (contemplando la adopción de medidas provisionales y cautelares en sede de sustracción internacional de menores) sino que el actual art. 20 RBII bis es reubicado, quedando como art. 12 en la sección relativa a la competencia judicial internacional en materia de responsabilidad parental. Este cambio, unido a la nueva formulación del artículo, que alude solo a las medidas que se adopten sobre el niño o sus bienes, suscita una duda relevante acerca de qué ocurre respecto de las medidas que se puedan solicitar en los procedimientos relativos a la crisis matrimonial. Ciertamente los menores son los principales destinatarios de estas medidas incluso en el marco de los procedimientos matrimoniales pero no cabe descartar que se solicitara alguna medida provisional respecto de uno de los cónyuges.

El nuevo art. 12 se ve afectado por la interpretación que del art. 20 RBI bis ha hecho el TJUE, en buena medida realizando una lectura restrictiva del alcance de la competencia del tribunal de la tutela provisional/cautelar ${ }^{64}$. Hasta el momento presente, el art. 20 RBII bis permite, en caso de urgencia, la adopción de medidas provisionales sobre personas o bienes presentes en un Estado miembro conforme a la legislación de dicho Estado miembro por un tribunal de ese Estado, aunque no sea el competente para el fondo. Las medidas tienen un carácter provisional en tanto dejarán de aplicarse cuando el tribunal competente para el fondo adopte la medida que considere apropiada.

El TJUE ha abordado el alcance del art. 20 RBII bis en varios asuntos, incorporando una serie de precisiones importantes: así, es necesaria la presencia del menor en el territorio de ese Estado, aunque no sea el de su residencia habitual ${ }^{65}$; estas medidas solo pueden adoptarse en caso de urgencia,

${ }^{63}$ El hecho de que la competencia del tribunal pueda derivar de materias fuera del ámbito de aplicación de los reglamentos europeos no altera esta valoración precisamente por su carácter limitado (temporal y territorialmente) y discrecional (el art. 16 formula esta solución como una posibilidad: «podrá resolver esa cuestión»), de manera que permite que, si el juez así lo prefiere, suspenda el procedimiento y remita la cuestión accesoria al juez competente para el fondo de la acción de responsabilidad parental conforme al reglamento.

64 DutTA, A. y Schulz, A., op. cit., nota 4, p. 20.

65 Asunto C-523/07, cit., supra nota 52, párr. 47. 
i. e., cuando no sea posible acudir al tribunal del fondo del asunto ${ }^{66} \mathrm{y}$ es conveniente que la autoridad del Estado que adopta la medida comunique a la autoridad competente sobre el fondo la adopción de dicha medida ${ }^{67}$. Precisamente el art. 12 añade un párrafo al apartado 1, introduciendo la obligación de informar al Estado miembro cuyos tribunales son competentes para el fondo del asunto de la adopción de una medida cautelar sobre el menor de conformidad con los cauces que prevé el propio artículo (bien directamente, bien a través de la autoridad central). Esta obligación existirá cuando el interés superior del niño lo exija, lo que confiere un cierto margen de apreciación al juez que adopta la medida.

Adicionalmente el TJUE ha establecido que las medidas provisionales adoptadas conforme a reglas de Derecho autónomo no pueden ser objeto de reconocimiento y ejecución conforme a las reglas del RBII bis (aunque no se excluye que puedan serlo conforme a la normativa nacional) ${ }^{68}$. Y también, en una lectura muy limitadora del art. 20 RBII bis, el TJUE ha indicado que la referencia del artículo a «las personas» incluye no solo al menor sino también a sus progenitores, lo que implicaría que para poder adoptar una medida provisional deberían estar todos presentes ${ }^{69}$. Esta exigencia, que ha sido muy criticada $^{70}$, se corrige en la propuesta al exigir el art. 12 que la medida se adopte en relación con «el niño» presente en el territorio de la autoridad del Estado miembro.

Más allá de los efectos de la jurisprudencia del TJUE, el art. 12 incorpora una regla de competencia judicial internacional provisional al establecer que las autoridades «tendrán competencia para adoptar medidas...», lo que explica el nuevo art. 48, que permite reconocer y ejecutar en otro Estado miembro las medidas cautelares adoptadas en virtud del art. 12, salvo que se hubieran dictado inaudita parte debitoris ${ }^{71}$, y con independencia de si la medida adoptada fue comunicada al juez del fondo del asunto ${ }^{72}$. La introducción de un foro de tutela cautelar alinea la propuesta con las reglas del CH1996, y sin duda redunda en una mejor protección del menor puesto que facilita la adopción de medidas cuando el tribunal del fondo no las haya dictado (y esto puede ser particularmente útil en supuestos de sustracción).

66 Asunto C-403/09 PPU, ECLI: EU:C:2009:810, párr. 42.

67 Asunto C-523/07, cit., supra nota 52, párrs. 54-56.

68 Asunto C-256/09, ECLI:EU:C:2010, párrs. 64-76.

69 Asunto C-403/09 PPU, cit., supra nota 66, párrs. 50-52.

70 En particular en casos de sustracción de menores, puesto que salvo que el progenitor left behind compareciera en ese procedimiento cautelar, no se podría otorgar la medida, KRUGER, TH. y SAMYN, L., op. cit., nota 3, p. 149.

71 Esta salvaguardia se alinea con las reglas existentes en el marco de Bruselas I. Del cdo. 40 puede colegirse que el reconocimiento de una medida provisional dictada inaudita parte quedará sujeto a las normas de Derecho autónomo de los Estados miembros, en línea con la jurisprudencia del TJUE en el asunto Purrucker I, tal y como se aclara en el cdo. 33 del Reglamento Bruselas I bis en el ámbito civil.

72 Conforme al cdo. 17, el incumplimiento de la obligación de comunicar la adopción de la medida no supone un motivo para negar el reconocimiento a dicha medida cautelar. 


\subsection{Relaciones con otros actos}

La propuesta de Reglamento incorpora un nuevo capítulo VIII donde se regulan las relaciones del Reglamento con otros actos. Los arts. 72 a 77 recogen parte de las disposiciones ya existentes a estos efectos en el RBII bis, en lo relativo a los tratados con la Santa Sede (art. 77 RBII bis), a los convenios entre Estados miembros (art. 59 RBII bis) y los convenios multilaterales (art. 60 RBII bis), si bien en este caso se elimina la referencia al Convenio de La Haya de 1980 del listado de textos sobre los que el Reglamento "primará» para introducir un nuevo art. 74 en el que se aclara que entre los Estados miembros será de aplicación el Convenio «de conformidad con lo dispuesto en el capítulo III del presente Reglamento».

De igual modo, el nuevo art. 75 (que retoma parte del presente art. 61) establece las relaciones entre el Reglamento y el Convenio de La Haya de 1996, aclarando la prioridad de las reglas de este último en los supuestos de sumisión, transferencia de competencia y litispendencia. Así, cuando el menor tenga su residencia habitual en un Estado miembro (y por tanto, se cumple la condición de la aplicación del Reglamento) será posible que, de conformidad con las reglas del CH1996, las partes se sometan a los tribunales de un Estado contratante del Convenio (art. 10 CH1996), o que el tribunal de un Estado miembro (de la residencia habitual del menor) pueda transferir su competencia a un tribunal de un Estado contratante del convenio (conforme al art. 9 CH1996) o inhibirse a favor del tribunal de un Estado contratante del convenio (art. 13 CH1996). Esta revisión servirá para resolver las dudas que hasta la fecha podían plantearse y que la actual formulación del RBII bis conduce a resolver a favor de la aplicación del Reglamento frente al Convenio, lo que había generado peticiones de reforma en el sentido ahora recogido en la propuesta de refundición ${ }^{73}$.

\section{CONCLUSIÓN}

Una vez estudiada la propuesta procede valorar su alcance. En este sentido podemos retomar los objetivos que esta se propone y contrastar si se logran o no. Así, la introducción explica que «el objetivo de la refundición es seguir desarrollando el espacio europeo de justicia y derechos fundamentales basado en la confianza mutua, suprimiendo los obstáculos que subsisten a la libre circulación de las resoluciones, en consonancia con el principio de reconocimiento mutuo, así como proteger mejor el interés superior del niño mediante la simplificación de los procedimientos y la mejora de su eficacia» ${ }^{74}$. Así pues, desde el inicio es manifiesta la concurrencia de dos principios subyacentes en las modificaciones de las reformas propuestas. Cabe preguntarse, pues, si y en qué medida se alcanzan.

\footnotetext{
73 Así, KRuger, Th. y SAmyn, L., op. cit., nota 3, pp. 152 y 154.

74 Propuesta, p. 2.
} 
Son numerosas las ocasiones en que la propuesta alude al interés superior del menor. En algunas este interés tiene una clara vertiente procesal, así cuando se retoma la idea del RBII bis de que las reglas de competencia judicial internacional reflejan el interés superior del menor (cdo. 14), o cuando se establecen medidas para facilitar la cooperación entre autoridades ( $v$. gr. cdos. 17, 18 y 46). En otras, tiene un contenido más sustantivo, como cuando se identifica la audiencia del menor (art. 20) o la posibilidad de expresar su opinión (por ejemplo, oponiéndose a la ejecución, art. 40) como un derecho que debe garantizarse en su interés. Es posible también encontrar referencias al interés superior del menor como criterio de interpretación (cdo. 13). Es decir, podría afirmarse que la propuesta de refundición del RBII bis adopta las pautas que establece el art. 3 de la CDN, en línea con lo estipulado en el citado cdo. 13. Lamentablemente otros aspectos que inciden en su protección y que están directamente vinculados con el ejercicio de derechos fundamentales (v. gr. en materia de acogimiento transfronterizo) no han recibido suficiente atención.

Por otra parte, es evidente que en ocasiones las reformas introducidas persiguen objetivos más relacionados con la integración europea (así cuando las reglas permiten alinear el texto con otros reglamentos europeos) y el reforzamiento del principio de confianza mutua aunque «vistan» como protección del interés del menor: esto es evidente en toda la regulación del procedimiento de retorno de menores tras una sustracción (arts. 25-26), en la eliminación del exequatur (arts. 30 ss.) o en la armonización de determinadas reglas (v. gr. arts. 32, 36, 38). Estas medidas reflejan en buena medida que la citada confianza mutua aún está lejos de alcanzarse y genera tensiones que incluso en este momento no pueden superarse sin una intervención del legislador europeo que, en cierta medida, refuerza soluciones mecánicas que no siempre pueden responder a la realidad.

De este modo, aunque abandonando todo esfuerzo simplificador, la propuesta de refundición del RBII bis consigue un objetivo realista y positivo: ofrecer soluciones para aquellos fallos identificados del sistema. Pero estas soluciones reflejan en ocasiones que aún estamos lejos de alcanzar el objetivo de la confianza mutua, y ello supone que la función integradora del Derecho internacional privado europeo se manifieste en muchas de las reglas de la propuesta con más fuerza que la consecución de los objetivos privatistas de la norma, i. e. la protección de los menores.

\section{RESUMEN}

\section{LA REFUNDICIÓN DEL REGLAMENTO BRUSELAS II BIS: DE NUEVO SOBRE LA FUNCIÓN DEL DERECHO INTERNACIONAL PRIVADO EUROPEO}

Cumplidos diez años desde la entrada en vigor del Reglamento (CE) 2201/2003, y con numerosos pronunciamientos del TJUE en estos años que han ido perfilando sus disposiciones, ha llegado el momento de revisar este Reglamento en profundidad. La Comisión ha presentado en 2016 una versión refundida del texto en la que se identifican seis problemas 
fundamentales que considera preciso abordar: la sustracción internacional de menores, la eliminación del exequatur, la ejecución de las decisiones extranjeras, la cooperación de autoridades, el acogimiento transfronterizo y la intervención del menor. Como indica la propuesta, la finalidad de esta revisión en última instancia sería la de proteger el interés superior del menor. Ahora bien, muchas de las nuevas disposiciones introducen medidas que conllevan una armonización de las normas procesales de los Estados miembros, produciendo una integración más intensa que sin duda permite potenciar el principio del reconocimiento y la confianza mutuos. Este trabajo analiza las novedades introducidas (en los seis puntos previstos y en otros muchos elementos del Reglamento) y la tensión entre la protección del interés superior del menor y el refuerzo del reconocimiento mutuo en el espacio judicial civil europeo.

Palabras clave: Reglamento Bruselas II bis, refundición, interés superior del menor, reconocimiento y confianza mutuos.

\section{ABSTRACT \\ REGULATION BRUSSELS II BIS RECAST: REFLECTIONS ON THE ROLE OF EUROPEAN PRIVATE INTERNATIONAL LAW}

Ten years after the Regulation (EC) 2201/2003 entered into force, and bearing in mind the jurisprudence of the European Court of Justice on the Regulation, the Commission believes that the time is ripe for a Regulation recast. Thus, in 2016 the Commission has presented its proposal. The text identifies six basic problems that are deemed to be in need of a thorough revision: international child abduction, the disposal of exequatur, the enforcement of foreign decisions, cooperation between authorities, cross-border placement of children and the hearing of the child. As the proposal highlights, the recast would aim at better protecting the best interest of the child. However, many of the new rules included entail direct harmonisation of procedural rules of Member States, which will result in a deeper integration that will foster the principles of mutual recognition and mutual trust among Member States. This article deals with the novelties of the Brussels II recast (both as to the six items previously identified as well as other new elements of the Regulation) and tackles the tension between the protection of the best interest of the child and the reinforcement of the principle of mutual recognition in the European area of civil justice.

Keywords: Brussels IIa Regulation, recast, best interest of the child, mutual recognition and trust. 